Chapter 2

\title{
Elaboration of Technologies for the Diagnosis of Tropical Hurricanes Beginning in Oceans with Remote Sensing Methods
}

\author{
A. G. Grankov, S. V. Marechek, A. A. Milshin, \\ E. P. Novichikhin, S. P. Golovachev, \\ N. K. Shelobanova and A. M. Shutko \\ Additional information is available at the end of the chapter \\ http://dx.doi.org/10.5772/53863
}

\section{Introduction}

Satellite passive microwave (MCW) radiometric methods are an important tool for determining the oceanographic and meteorological parameters that affect the energy exchange in the ocean-atmosphere system (SOA), such as sea surface temperature, wind speed, the total amount of water vapor in the atmosphere, integral water vapor content of the clouds, precipitation intensity, and also especially important to study the characteristics of the cyclonic areas of the ocean are the vertical turbulent fluxes of heat, moisture and momentum. These satellite measurements can also give indirect information about the factors important from the point of formation of tropical storms processes in the ocean and on its bottom, outside of direct line of sight remote means. Their use in this case "allows researcher to look into the ocean column on the surface of which as a kind of screen are projected the various images of deep-water processes" [1].

The long-term goal of this research is the creation of methods and technologies for diagnosing the origin of tropical hurricanes (THs) in the areas of the ocean, which are regular sources, the origin of hurricanes on basis of the data of passive MCW microwave radiometric measurements from satellite, ship, buoy measurements and results of mathematical modeling of the behavior of the parameters of the ocean-atmosphere system (SOA) at different stages: the stage that precedes the appearance of $\mathrm{TH}$; the appearance $\mathrm{TH}$; the stage of SOA relaxation after $\mathrm{TH}$ appearance. 
The important theoretical purpose of the work is the search for effects and regularities, which can explain the reasons and circumstances under which THs appearance is inevitable.

\section{Behavior of parameters of the atmosphere immediately before the appearance of hurricanes}

In this section are presented some results of the study of the SOA reaction on passing the powerful Hurricane Katrina in August 2005 in the Florida Straits in the area of the buoy station SMKF1 (Sombrero Key) as well as the results of a behavior of the system in the period of time preceding the beginning and development of the Hurricane Humberto in the Gulf of Mexico in September 2007 at the point of the buoy station 42019. For these time periods an analysis of the following synoptic variations of atmospheric and oceanic characteristics were conducted: These include air temperature, humidity, pressure and wind speed in the nearsurface 10-th meter layer in area of the stations SMKF1 and 42019, vertical turbulent fluxes of sensible and latent heat at the sea-water boundary calculated with the measurement data the stations SMKF1 and 42019 and integral (total) water vapor content and enthalpy of the atmosphere calculated by integration of the air humidity and temperature within the height range 10-10000 meters.

The source of information on the earth-based data is the American center - National Data Buoy Center NOAA (NDBC); the data of regular measurements from the microwave radiometers, SSM/I (Special Sensor Microwave/Imager) of the meteorological satellite F15 DMSP and AMSR-E (Advanced Microwave Scanning Radiometer) of the satellite EOS Aqua were used as the source of satellite data. The technical characteristics of these radiometers are given in references [2] and [3], respectively.

Spacious network of meteorological of the NOAA stations, in particular, the stations situated in the Gulf of Mexico and the equatorial zone of the Pacific Ocean provide exclusively measurements of the parameters of the ocean surface and near-surface atmosphere. Meteorological means of observation from these stations are not able to give information on the vertical distribution of temperature and humidity in the atmosphere. This problem can be solved by means of use of measurement data of the multichannel MCW radiometer SSMIS (Special Sensor Microwave Imager/Sounder) from satellites DMSP F16 and F17 [4]. In addition to this function of the scanner, this device is able to determine the atmosphere temperature and humidity at various heights. However, a periodicity of remote sensing these atmospheric characteristics (once per day) is not enough for studying such fast processes as tropical hurricane formation, with noticeably varying characteristics during several hours.

The method of combining the data of the buoy measurements of the atmospheric near-surface layer and the ocean surface parameters with data obtained from satellite MCW measurements has been developed, which provide information on the air temperature and humidity, not only in the near-surface atmosphere but also in overlying atmospheric layers. This technique allows the determination of values of the atmosphere temperature and hu- 
midity at its various horizons (the property of satellite MCW radiometric measurements) and hourly (the property of buoy meteorological measurements).

\section{Dynamics of meteorological parameters measured from the stations SMKF1 and 42019}

\subsection{Station SMKF1 (TH Katrina)}

The station SMKF1 from the NDBC data arsenal is used as the reference point in the Florida Straits $\left(24.38^{\circ} \mathrm{N}, 81.07^{\circ} \mathrm{W}\right)$ when analyzing an influence of the Hurricane Katrina on the atmospheric parameters. The nearest distance between a trajectory of Katrina and this station was $\sim 120 \mathrm{~km}$ in the noon of 26 August 2005, by this moment the hurricane has passed about $800 \mathrm{~km}$ from the place of its formation near the Bahamas.

The NDBC data in an area of the station SMKF1 between 21 and 31 August 2005 was analyzed. It can be observed here that significant contrasts of the near-surface air parameters with respect to their undisturbed (background) values are appearing before the coming of Hurricane Katrina and after it moving off: the variations of the air temperature, humidity and pressure are about $-6^{\circ} \mathrm{C},-15 \mathrm{mb}$ and $-13 \mathrm{mb}$, respectively.

Fig. 1 illustrates variations of the air temperature $t_{a}$ and pressure $\mathrm{P}$ in the atmosphere nearsurface layer between the 21st and 31st August 2005 recorded by sensors of the SMKF1 station as well as computed values of the near-surface air humidity (water vapor pressure) e. These results were obtained using the data from previous studies of the relationship of the parameter e with the difference of water and air temperatures in various zones of the world ocean derived in [5]: the NOAA buoy stations are not includes direct measurements of the air humidity. Fig. 1 presents the smoothed results of station measurements of the parameters $t_{a}, \mathrm{P}$ and calculated estimates of the parameter e. A smoothing is compiled with the standard means of the computer program ORIGIN Adjacent Averaging with the 3-hour interval of averaging of the hourly samples. Initial data level from the SMKF1 sensors was 240 hourly samples for each of the parameters $\mathrm{t}_{\mathrm{a}^{\prime}}$ e and $\mathrm{P}$, characterizing the stage proceeding an appearance of the Hurricane Katrina in an area of the station SMKF1 (21-24 August), the stage of its passing this area (25-29 August) and the stage of the SOA relaxation (30-31 August). These results suggest the need to apply an idea of the explosive effects in the atmosphere during the THs activity.

Results of the linear regression analysis show close interrelations between variations of the near-surface air temperature and humidity, the coefficient of correlation of the parameters $t_{a}$ and e is 0.94 . On the basis of the data of buoy meteorological measurements and using the technique cited in [6] computed values of internal energy (enthalpy) of the near-surface atmosphere in the period from 21 to 31 August 2005 were carried out. When passing the point SMKF1, Hurricane Katrina collects the heat energy from the atmosphere near-surface layer, according to this estimate it is reducing roughly to $32500 \mathrm{~J} / \mathrm{m}^{2}$ in this period. 

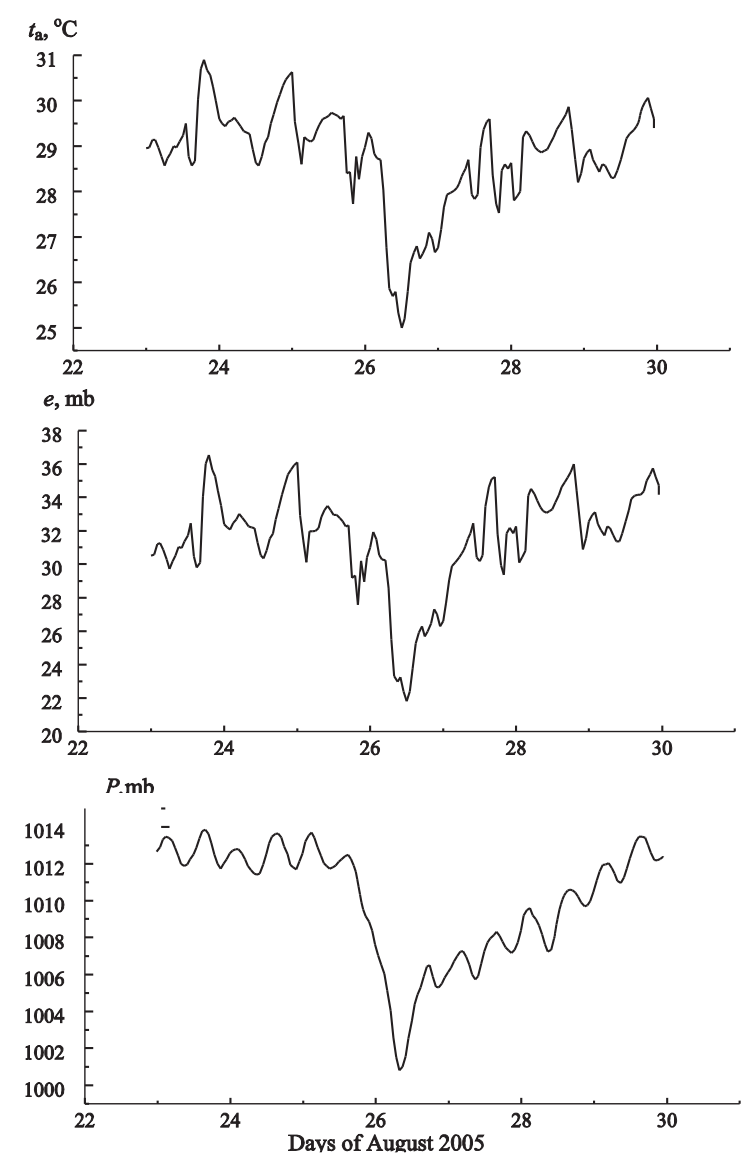

Figure 1. Variations of the near-surface temperature $t_{a}$, humidity $e$, pressure $P$ in the area of location of the station SMKF1 in the Florida Strait during passing the TH Katrina in August 2005.

\subsection{Station 42019 (TH Humberto)}

Hurricane Humberto was born in the middle of September 2007 in the Gulf of Mexico, it was not as intensive as Hurricane Katrina, but it is important in these studies as its source area coincided with the location of the buoy station 42019 situated at coordinates $27.91^{\circ} \mathrm{N}$, $95.35^{\circ} \mathrm{W}$. This peculiarity allows the monitoring of parameters of the atmospheric near-surface layer (as well as parameters of overlying layers when using data of simultaneous MCW radiometric measurements) over various stages of forming the hurricane. According to the data measurements from the station 42019 this point is characterized by a strong changeability of parameters of the atmospheric near-surface layer in the period of forming Hurricane Humberto: variations of the air temperature, humidity, pressure, and wind speed amounted to $3^{\circ} \mathrm{C}, 8 \mathrm{mb}, 5 \mathrm{mb}$ and $7 \mathrm{~m} / \mathrm{s}$, respectively (see Fig. 2). 

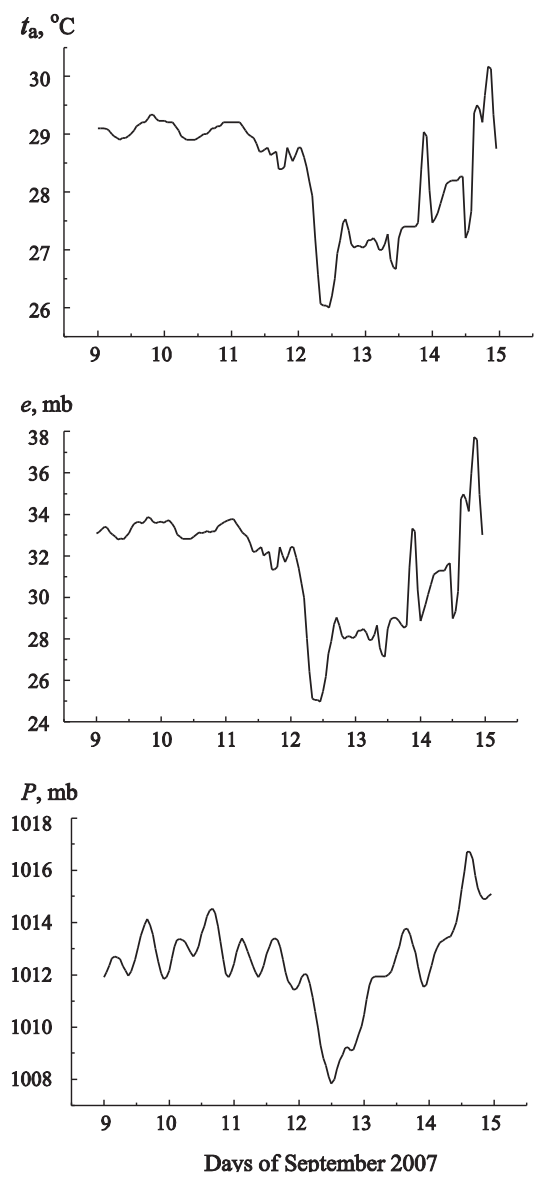

Figure 2. Variations of the near-surface temperature $t_{a}$, humidity e, pressure $P$ from the measurement data of the station 42019 in the Gulf of Mexico during the starting the TH Humberto in September 2007.

Variations of the near-surface air humidity in the period from 9th to 14th September practically repeat variations of the near-surface air temperature: the coefficient of their correlation is 0.97 . The near-surface air pressure is sharply declining at the stage of this hurricane development (12 September). The atmospheric near-surface layer enthalpy was computed between 9th and 14th September 2007 in the area of location of the station 42019: it follows from the results of computation that the enthalpy has been reduced by $12500 \mathrm{~J} / \mathrm{m}^{2}$ during the development of Hurricane Humberto. An analysis of variations of the ocean surface temperature during the passing the Hurricane Katrina passed the station SMKF1 (22-31 August 2005) and during the period of formation and development of the Hurricane Humberto (8-16 September 2007) has been fulfilled - these results are shown at the Fig. 3. To emphasize the character of behavior of the ocean surface temperature, the data of buoy measurements 
are approximated with the standard means of the computer technique ORIGIN (Sigmoidal), which produces the stick-slip motion of original dependencies. Figure 3 demonstrates the "jump" of the ocean surface temperature values in area of the station SMKF1 caused by passing the Hurricane Katrina is in a few times more in comparison with this phenomena observed during beginning the Hurricane Humberto.

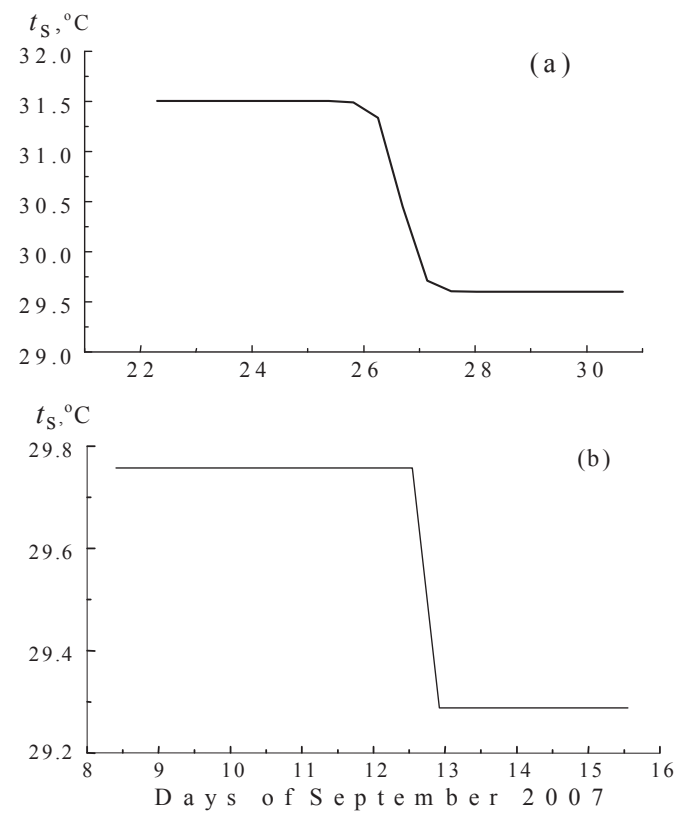

Figure 3. Character of changes of the ocean surface temperature $t_{s}$ : (a) an area of the station SMKF1 during passing the TH Katrina: (b) an area of the station 42019 in the period of forming the TH Humberto.

\section{Dynamics of the surface heat and moisture fluxes}

Resting upon the data of buoy measurements of the ocean surface temperature, the nearsurface air humidity estimates and wind speed we computed the values of sensible $\mathrm{q}_{\mathrm{h}}$ and latent $\mathrm{q}_{\mathrm{e}}$ heat at the air-sea boundary using the well-known in dynamic meteorology formulas of the Global Aerodynamic Method) - so called Bulk Formulas were justified in [7]. Due to this approach the values $\mathrm{q}_{\mathrm{h}}$ and $\mathrm{q}_{\mathrm{e}}$ are characterized with the following relationships:

$$
\begin{gathered}
q_{h}=c_{p} \rho c_{t}\left(t_{s}-t_{a}\right) V ; \\
q_{e}=L \rho(0.622 / P) c_{e}\left(e-e_{o}\right) V,
\end{gathered}
$$


i.e. they are become apparent through following parameters of the SOA - the air temperature $t_{a}$, pressure $\mathrm{P}$, humidity e and wind speed $\mathrm{V}$ in the near-surface atmosphere, as well as through the ocean surface temperature $t_{s}$ and proper for this the maximal value of the air humidity $\mathrm{e}_{\mathrm{o}}$. As the constant of proportionality in these relations are served the numbers of Schmidt $c_{t}$ (heat exchange), Dalton $c_{e}$ (moisture exchange), the specific heat of evaporation $(\mathrm{L})$, the specific air heat under constant pressure $\left(\mathrm{c}_{\mathrm{p}}\right)$, and its density $(\mathrm{Q})$. Below some results of computing the heat fluxes with reference to the stations SMKF1 and 42019 based on the buoy measurements in these areas of the Gulf of Mexico are presented.

\subsection{Station SMKF1}

Figure 4 shows some results of computation of the heat fluxes (with 3-hour averaging). One can observe an influence of passing the Hurricane Katrina through the station SMKF1 seen in the form of appreciable reducing of the heat fluxes, about $20 \mathrm{~W} / \mathrm{m}^{2}$ (from 30 to $10 \mathrm{~W} / \mathrm{m}^{2}$ ) for the fluxes of sensible heat, and about $150 \mathrm{~W} / \mathrm{m}^{2}$ (from 350 to $200 \mathrm{~W} / \mathrm{m}^{2}$ ) for the fluxes of latent heat. This result demonstrates an effect of smoothing the heat contrasts between the ocean surface and near-surface atmosphere due to the effects of the passing of the hurricane.
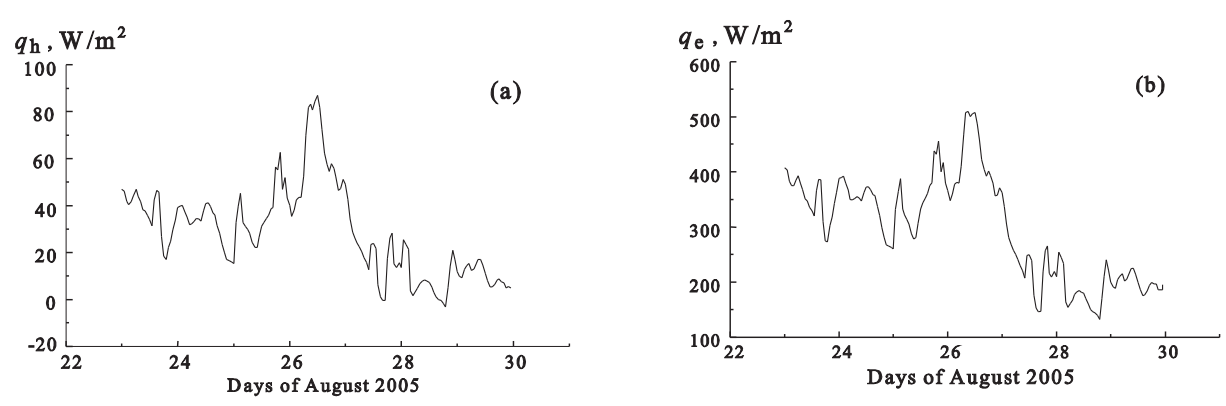

Figure 4. Variations of sensible (a) and latent (b) heat fluxes at the ocean surface in an area of the station SMKF1 location in the period of passing the TH Katrina in August 2005.

The moment of passing of the hurricane over the station SMKF1 (noon of 26 August) is accompanied by a positive increase of the parameters $\mathrm{q}_{\mathrm{h}}$ and $\mathrm{q}_{\mathrm{e}}$, which amount to 80 and 500 $\mathrm{W} / \mathrm{m}^{2}$, respectively.

\subsection{Station 42019 (Hurricane Humberto)}

Figure 5 shows results of computing the fluxes of sensible and latent heat and impulse (with the 3-hour smoothing); one can observe here a sharp maximum peak of the values $\mathrm{q}_{\mathrm{h}}$ and $\mathrm{q}_{\mathrm{e}}$ simultaneously, which falls at the noon of 12 September 2007 that coincides with the data of ground observations of the Hurricane Humberto development. 

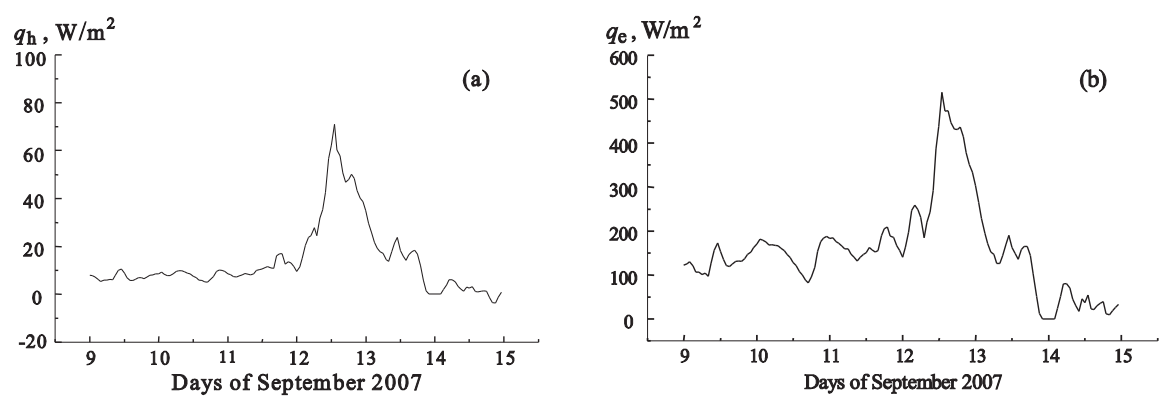

Figure 5. Variations of sensible (a), latent (b) heat and impulse (c) fluxes at the ocean surface in area of the station 42019 location in period of beginning the Hurricane Humberto in September 2007.

Average values of the heat and moisture fluxes at the stage preceding TH Humberto appearance (9-12 September) amount to $5 \mathrm{~W} / \mathrm{m}^{2}, 150 \mathrm{~W} / \mathrm{m}^{2}$ and $0.05 \mathrm{~N} / \mathrm{m}^{2}$, respectively, and their maximal values at the stage of its development in the noon of 12 September reach to 75 $\mathrm{W} / \mathrm{m}^{2}, 530 \mathrm{~W} / \mathrm{m}^{2}$ and $0.2 \mathrm{~N} / \mathrm{m}^{2}$. Notably, that maximal value of the total (sensible+latent) heat fluxes in area of the station $42019\left(\sim 600 \mathrm{~W} / \mathrm{m}^{2}\right)$ is close to the estimate cited by Golytsin for tropical latitudes [8]. Also, this value is comparable with the total heat fluxes values in the Newfoundland energy active zone of the North Atlantic, which is subjected regularly to influence of powerful mid-latitude cyclones, which in compliance with the data of experiments NEWFOUEX-88 and ATLANTEX-90 reached to values of $800 \mathrm{~W} / \mathrm{m}^{2}$ in March 1988 and April 1990 [9].

Figure 6 demonstrates variations of the heat and moisture fluxes in the period 17-20 September at the stage of relaxation of the SOA parameters in area of the station 42019 after the development of Hurricane Humberto and it's leaving this area.
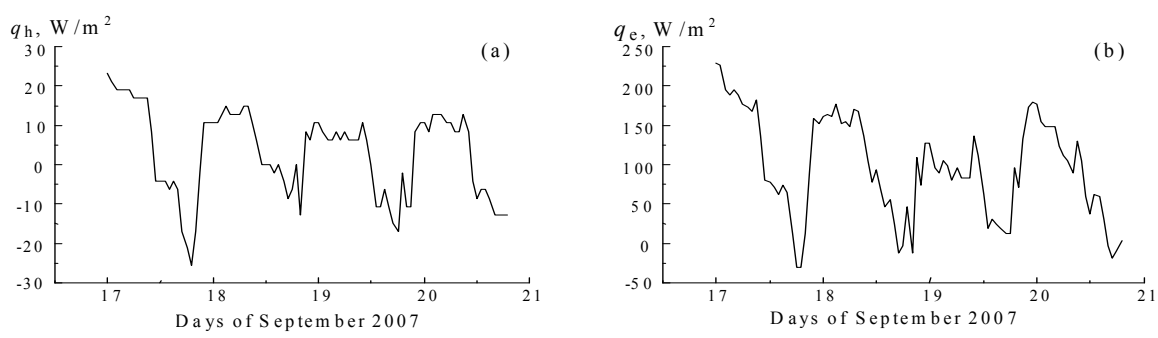

Figure 6. Behavior of the sensible (a) and latent (b) heat fluxes at the ocean surface in area of the station 42019 location after Hurricane Humberto's appearance.

It is seen from the illustration that average values of the parameters $\mathrm{q}_{\mathrm{h}}$ and $\mathrm{q}_{\mathrm{e}}$ are a few times under their limit values observed at noon on the 12th September. One interesting peculiarity manifests itself - the oscillatory character of variations in the heat and moisture fluxes in this time with the oscillation period closed to 24 hours, i.e. to the diurnal cycle. In addition, the 
sensible heat fluxes are alternating, that is the processes of heat transfer from the ocean surface to the atmosphere are alternating with the processes of heat transfer from the atmosphere to the ocean surface; this phenomenon was not observed in the period between 9th and 12th September preceding the appearance of Hurricane Humberto (see Fig. 2). This effect is similar to the effect of excitation of oscillations in high-Q resonant systems as the ringing circuits in radio-engineering described in [10] for example.

\section{Dynamics of integral water vapor content and enthalpy of the atmosphere}

\subsection{Technique of determination of the temperature and humidity of the atmospheric upper layers}

The sought dependences $t_{a}(h)$ and $и ~ Q(h)$ are found in the form of exponential functions $t_{a}(h)$ $=\mathrm{t}_{\mathrm{a}}(0) \exp \left(-\mathrm{K}_{\mathrm{t}} \mathrm{h}\right) ; \mathrm{Q}(\mathrm{h})=\mathrm{Q}(0) \exp \left(-\mathrm{K}_{\mathrm{Q}} \mathrm{h}\right)$ providing a minimal root-mean-square error (discrepancy) between measured by the MCW radiometers SSM/I и AMSR-E values of the SOA brightness temperatures and their simulated (model) estimates. With the dependences $t_{a}(h)$ and $\mathrm{Q}(\mathrm{h})$ the linear and integral absorption of radiowaves as well as the brightness temperatures of the SOA natural MCW radiation in various atmospheric layers for all satellite MCW radiometric channels are computed using the-known plane-layer model of natural microwave radiation of the system [11, 12].

As the radiometers SSM/I and AMSR-E are the multi-channel systems, their measurement data seems to be sufficient for determination of the coefficients $\mathrm{K}_{\mathrm{t}}$ and $\mathrm{K}_{\mathrm{Q}}$ required for retrieving the dependencies $t_{a}(h)$ and $\varrho(h)$ over the ocean. The value of discrepancy between simulated and measured estimates of the SOA brightness temperature is computed both with ascending as descending satellite orbits falling into cells $0.25^{\circ} \times 0.25^{\circ}$ centralized about the stations SMKF1 and 42019 for the following spectral and polarization channels of the radiometers SSM/I and AMSR-E: a) $37 \mathrm{GHz}(0.81 \mathrm{~cm}), 19 \mathrm{GHz}(1.58 \mathrm{~cm})$, vertical and horizontal polarizations; $22.235 \mathrm{GHz}(1.35 \mathrm{~cm})$, vertical polarization (radiometer SSM/I and b) $36.5 \mathrm{GHz}$ $(0.82 \mathrm{~cm}), 18.7 \mathrm{GHz}(1.6 \mathrm{~cm}), 23.8 \mathrm{GHz}(1.26 \mathrm{~cm})$, vertical and horizontal polarization (radiometer AMSR-E).

This developed technique allows the computation of approximately values of the temperature and humidity of the atmosphere at various horizons for estimating its integral characteristics such as the integral water vapor content and enthalpy (heat content), for example. It seems that mainly the atmosphere integral characteristics will be informative in an analysis of the SOA dynamics in zones of activity of the tropical hurricanes in spite of the fact that the real profiles of the air temperature and humidity can be appreciably different from the exponential ones.

Resting upon the buoy data on the air humidity in the near-surface layer and the computed estimates of this parameter in overlying atmosphere layers the integral water vapor content of the atmosphere (IVA) Q in the layer 10-10000 m was computed. Comparing the results of 
computing the parameter $\mathrm{Q}$ with its satellite estimates derived with the radiometer SSM/I in area of the station SMKF1 and the radiometer AMSR-E in area of the station 42019 was made. Besides, the calculation estimates of the atmosphere enthalpy for various its layers were obtained in areas of activity of the Hurricanes Katrina and Humberto.

\subsection{Dynamics of IVA in area of the station SMKF1}

Figure 7 compares the estimates of the IVA variations in area of the station SMKF1 during the period 1-30 August 2005 computed by a layer-wise integrating of the air humidity at various heights with the satellite estimates of the parameter $Q$ derived with the measurement data from the radiometer SSM/I using the known technique [13]. It can be observed here the appreciable variations of the parameter $Q$, which are coincide with the time of passing the Hurricane Humberto through the station SMKF1, when the maximum of the nearsurface heat fluxes was observed in the noon 25 August.

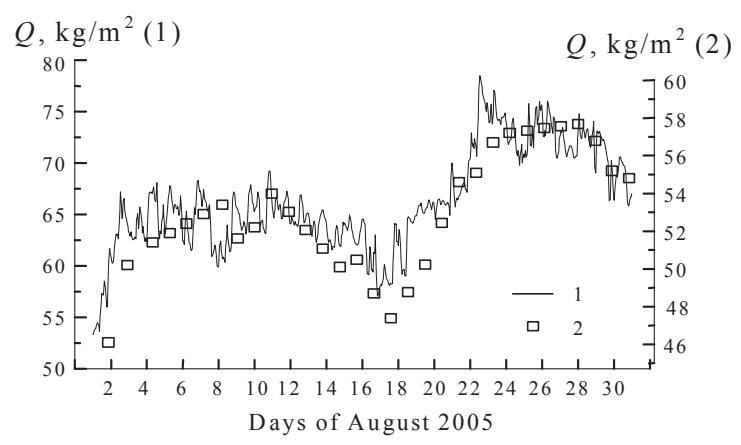

Figure 7. Comparing the estimates of the atmosphere integral water vapor content $\mathrm{Q}$ in area of the station SMKF1: 1 data of computing for the layer 10:10000 m; 2 - data of measurements of the radiometer SSM/I.

A difference between the absolute values of the computed and satellite estimates of the parameter $\mathrm{Q}$ can be explained by the fact that when modeling the SOA brightness temperature did not allow for its increase caused by the cloudiness and precipitation, which are registered by the satellite radiometer SSM/I. Irregularity of remote sensing an area of the SMKF1 station and availability of noticeable gaps in the satellite measurements is an important consideration also. Though, one can mark a good compliance of relative changes (variations) of the both estimates; this is essentially for validation of the developed technique of determination of the air temperature and humidity and especially, of their changeability at various horizons of the atmosphere under arising (passing) the tropical hurricanes.

\subsection{Dynamics of IVA in area of the station 42019}

The IVA estimates was derived in the area of station 42019 in the period 6-15 September including the stages of the formation of Hurricane Humberto and compared the satellite 
estimates of the parameter $\mathrm{Q}$ with the data of measurements from the radiometer AMSRE (see Fig. 8).
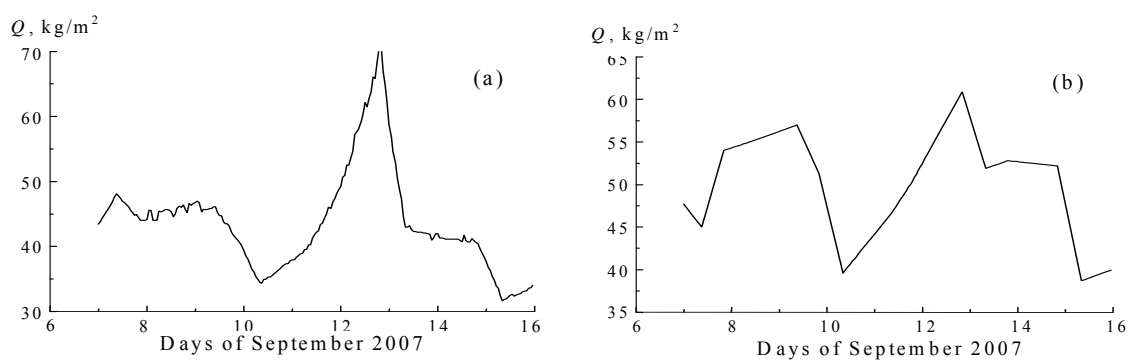

Figure 8. Estimates of the atmosphere integral water vapor content Q in area of the station 42019: (a) - data of computation for the atmosphere layer 10:10000 m; (b) - data of measurements from the radiometer AMSR-E.

It is seen from Fig. 8, that the formation of Hurricane Humberto is accompanied by increases of the value of $\mathrm{Q}$ (in the noon of 12 September); one can observe that maximum of $\mathrm{Q}$ (in the noon 12 September) happens together with maximums of fluxes of sensible, latent heat. The peak of values of $Q$ on 12th September precedes the fragment (7-9 September) with increased water vapor content of the atmosphere.

Figure 9 compares the satellite and simulated estimates of the parameter $Q$ after Hurricane Humberto left the area of station 42019 for the time interval 13-20 September. It follows from the illustration that a reducing IVA value occurred in this period, which has an oscillatory characteristic, similar to the case of the near-surface fluxes of sensible and latent heat.

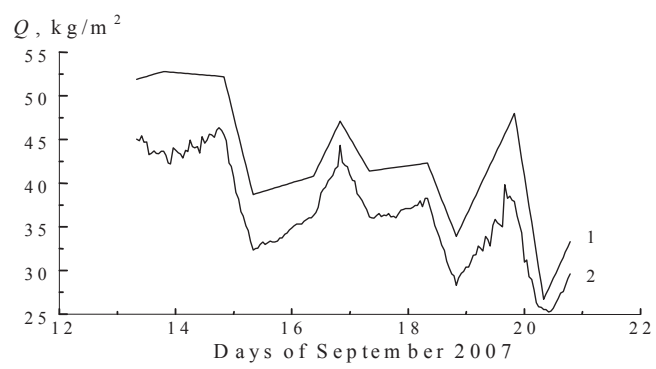

Figure 9. Compare of satellite (1) and simulated (2) estimates of the atmosphere integral water vapor content $Q$ after leaving by the Hurricane Humberto an area of the station 42019.

\subsection{Dynamics of the atmosphere enthalpy in areas of the stations SMKF1 and 42019}

Variations of the enthalpy (heat content) were computed of various atmospheric layers in areas of the stations SMKF1 and 42019 in periods of activity of the Hurricanes Katrina and 
Humberto. Figure 10 demonstrates some results of computation of the enthalpy J for the layer 10-10000 m.
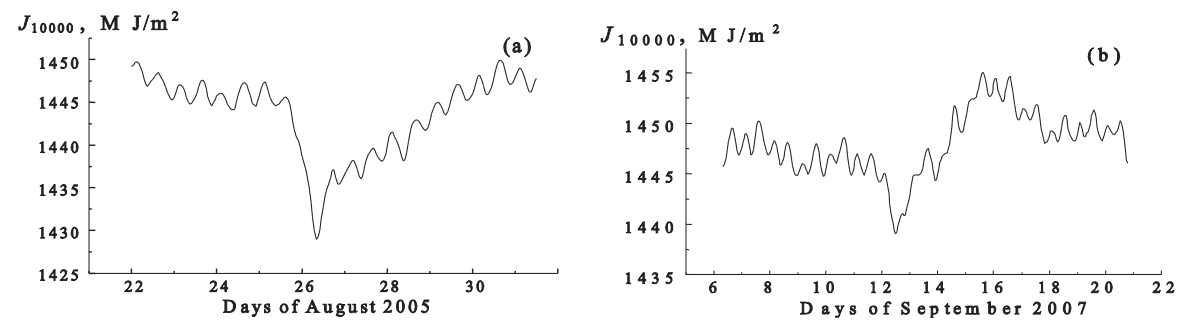

Figure 10. Variations of the atmospheric enthalpy $J_{10000}$ during passing Hurricane Katrina the station SMKF1 (a) and the formation of Hurricane Humberto in area of the station 42019 (b).

This illustration shows that during passing Katrina the station SMKF1 and arising Hurricane Humberto in area of the station 42019 we can observe a sharp reduction of the $J_{10000}$ value. This reduction is of the resonant type and accompanied by a strong increase in the vertical turbulent heat and moisture fluxes at the ocean-atmosphere boundary. Thus, the hurricanes cause a reduction of the atmosphere in these areas occurs, just like this effect occurs for the mid-latitude cyclones in the Newfoundland energy active zone of the North Atlantic in the experiment ATLANTEX-90 as shown in [9].

\section{Effect of accumulation of the atmoshere water vapor in the storm situations}

The long-term goal is to study some peculiarities of behavior of the atmosphere heat and microwave radiation characteristics in waters observed by contact and distant means for situations preceded to appearance of the storms.

The research areas are: an area of the station SMKF1 (Sombrero Key) in the Florida Straight in August 2005; a shore of the Black Sea (Gelendzik, territory of the South branch of the P.P. Shirshov Institute of Oceanology Russian Academy of Sciences) in September and October 2010 before the appearance of an intensive storm in 1 October).

Using meteorological and satellite microwave radiometric data comparison of the behavior of near-surface air humidity, fluxes of sensible and latent heat, total water vapor content of the atmosphere, as well as the microwave radiation characteristics of the water surface-atmosphere system were carried out in the periods before the appearance of Hurricane Katrina in area of the station SMKF1 and the development of sea storm in the area of the Gelendzik test site This effect is similar to the effect of a heat accumulation in the atmosphere water vapor observed in the Florida Straights in August 2005 when a clear effect of the monotonous strengthening of the integral water vapor content in the atmosphere was 
observed in the area of station SMKF1 before the atmospheric perturbations caused by appearance the Hurricane Katrina. In both cases the effect of accumulation of the water vapor in the atmosphere was observed.

\subsection{The Black Sea experiment: general description and results}

Research on the atmosphere parameters were carried out in a near-shore zone of the Black Sea. The measurements were conducted from 11th September until 10th October 2010 in area of the Blue Bay, which is located four kilometers west of Gelendzik Bay. Some data have been derived including for cloudless atmosphere and a calm sea situation and for the situation preceding a storm appearance. Devices of the measuring complex were placed on the pier end (Fig. 11). The pier has a length about $200 \mathrm{~m}$; the depth of water is $7 \mathrm{~m}$.

Besides traditional meteorological sensors a MCW radiometer mounted at the scanning platform was used. The radiometer operated at the wavelength $1.35 \mathrm{~cm}$, i.e. in the line of attenuation of the atmospheric water vapor, which helps estimate a total water vapor content of the atmosphere. The scanning of a hemisphere of space was realized in five fixed directions on an azimuth through 30 degrees. Scanning in an angle of elevation was conducted by slow change of an angle from zenith to a nadir and inverse.
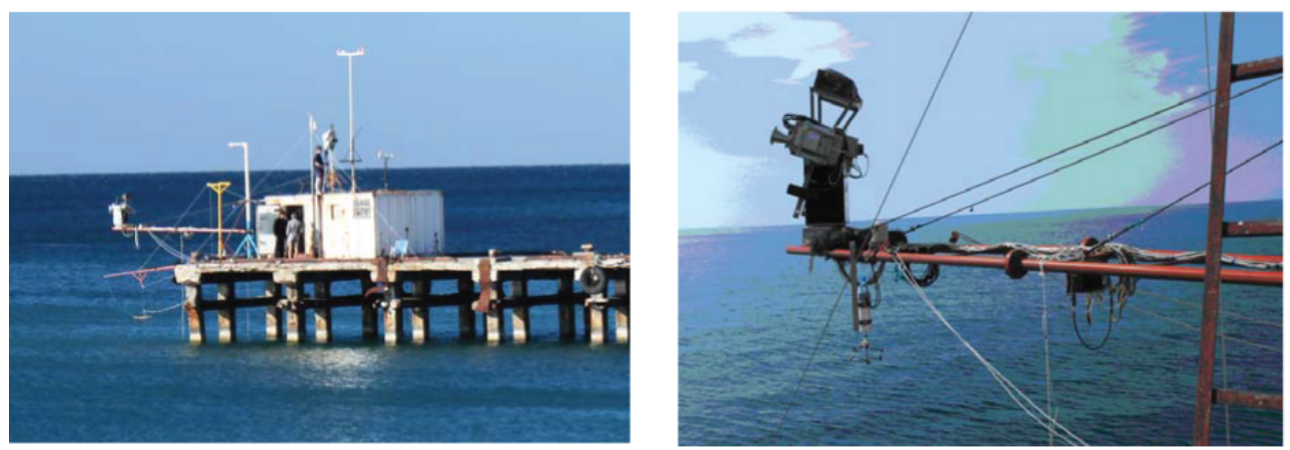

Figure 11. Measuring complex (left) and scanning platform (right).Ю

Figure 12 presents measured scans of the atmosphere brightness temperatures at the wavelength $1.35 \mathrm{~cm}$ as the functions of the azimuth angle and the angle of elevation during the period from 23 to 30 September preceding to the storm appearance (the storm has passed the test site on 1 October). It is seen from Fig. 12 the increase of minimal and maximal values of the atmosphere brightness temperature measured under positions of the scanning platform 0 and 90 degrees respectively. 


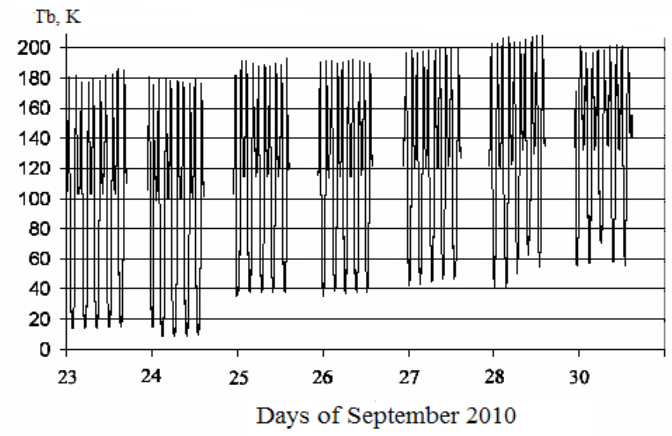

Figure 12. Brightness temperature $\mathrm{T}^{\mathrm{b}}$ for the azimuth scans of the atmosphere at the wavelength $1.35 \mathrm{~cm}$ before the storm approach into the Blue Bay.

\subsection{Dynamics of heat fluxes}

Results of meteorological measurements at the pier show the effect of increasing the nearsurface air temperature and humidity before the storm came into the Blue Bay area. In this period an accumulation of heat in the near-surface air water vapor occurred; its specific heat content was increased by $61 \mathrm{KJ} / \mathrm{m}^{2}$. So a sizeable increment of the air enthalpy in comparison with the storm situation in the Florida Straight in August 2005 (when Hurricane Katrina approached station SMKF1) for example is caused by essentially more variations of the temperature and humidity of the near-surface air. The vertical heat and latent fluxes were estimated with the bulk-formulas with use of the direct measurements of the air and water temperature as well as the near-surface wind speed; its results are presented in Fig. 13.

It is seen from Fig.13 that as the storm approaches there is a decrease of the sensible heat flux from 40 to $100 \mathrm{~W} / \mathrm{m}^{2}$ and latent heat flux from 225 to $10 \mathrm{~W} / \mathrm{m}^{2}$ occurred. Before an approach of the sea storm, the water surface gave up its heat to the near-surface air, but about the day before the storm's appearance in Blue Bay a characteristic of the heat interchanges in the water/air interface was changed. 

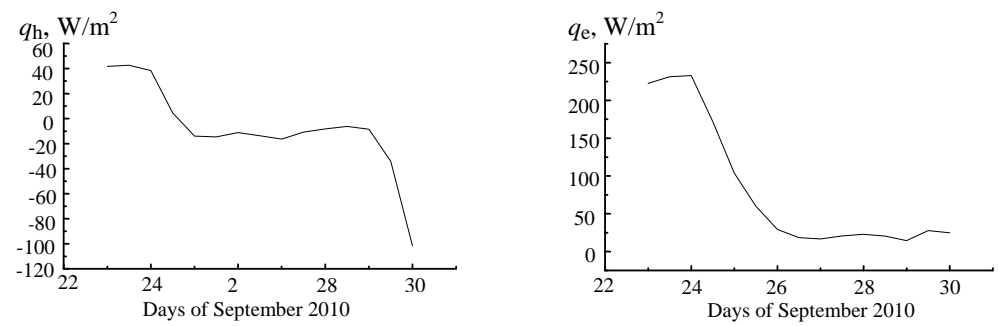

Figure 13. Variations of sensible $\mathrm{q}_{\mathrm{h}}$ and latent $\mathrm{q}_{\mathrm{e}}$ heat fluxes caused by the storm activity in the Blue Bay.

\subsection{Comparison of sea and satellite measurements}

A comparison of the variations of the near-surface air temperature and humidity measured directly from the pier by the meteorological sensors with those obtained from the EOS Aqua radiometer AMSR-E at the wavelength $1.26 \mathrm{~cm}(23.8 \mathrm{GHz})$ in the sea area bordered by Blue Bay from the Black Sea side was carried out. A comparison of satellite measurement data proper for the Blue Bay will be uncorrected, as its sizes are considerably less in comparison with the spatial resolution of the AMSR-E channel $1.26 \mathrm{~cm}$. Figure 14 show results of comparison of the near-surface air temperature and humidity (a), the brightness temperature measured by the AMSR-E radiometer at the wavelength $1.26 \mathrm{~cm}(\mathrm{~b})$; the brightness temperature measured from the pier by the radiometer operating at the wavelength $1.35 \mathrm{~cm}$ (c). The sizes of selected area are confirmed to the sizes the satellite "spot", which linear sizes for the AMSR-E radiometer $23.8 \mathrm{GHz}$ are of $40 \times 60 \mathrm{~km}$ with the center coordinated of $44^{\circ} \mathrm{W}, 38^{\circ} \mathrm{E}$.

4

Fig.14 illustrates a similarity of reactions of the SOA characteristics such as the near-surface air temperature and humidity measures from the pier as well as the SOA brightness temperature in the resonant region of the wavelength of attenuation of the radiowaves in the atmospheric water vapor, with any methods of the MCW passive radiometric observation means independently (from the pier or from the space). The effect of "pumping" the near-surface air temperature and humidity before the approach of Hurricane Katrina in the area of the SMKF1 station was observed, also during a progress of the Hurricane Katrina in the Florida Straights (station SMKF1) in August 2005 (Fig. 15). The estimates of the parameter $\mathrm{Q}$ were obtained from the measurements of the radiometer AMSR-E at the wavelength $1.26 \mathrm{~cm}$. 

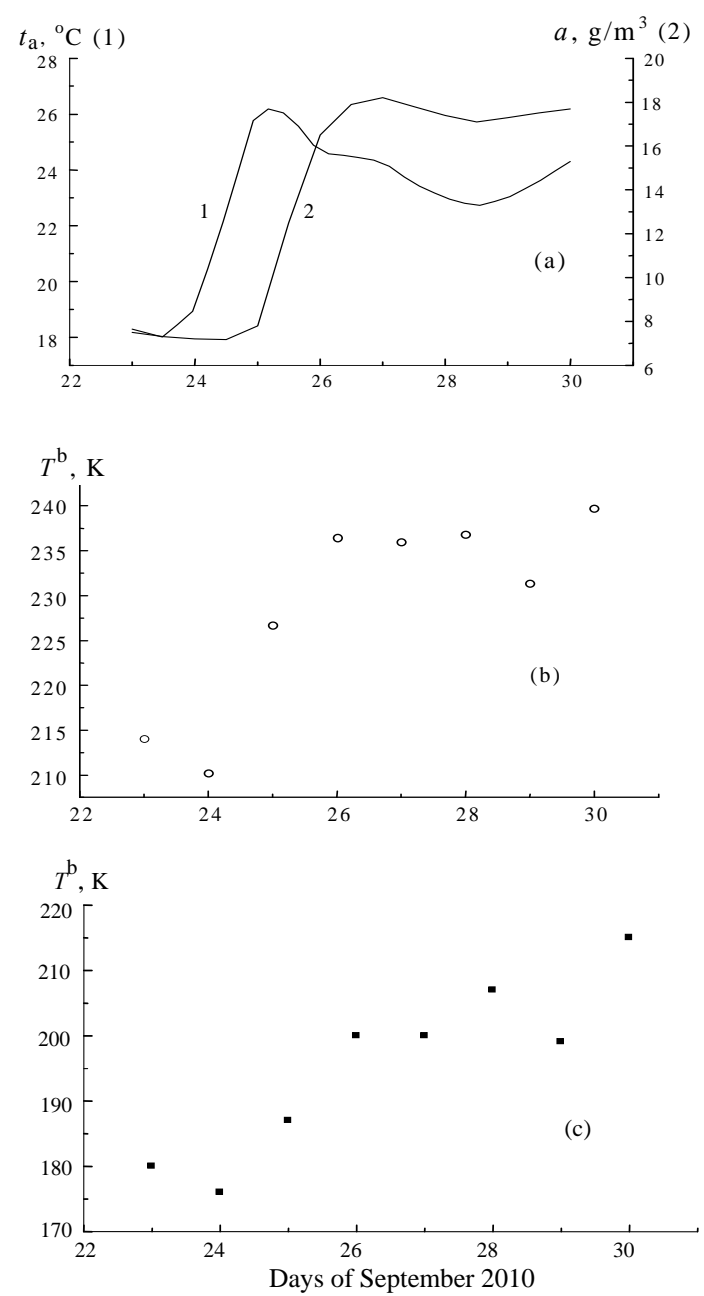

Figure 14. Variations of heat and thermal microwave characteristics of the atmosphere before approach of the sea storm into Blue Bay: (a) - temperature (1) and humidity (2) of the near-surface air; (b) - AMSR-E brightness 
temperature at the wavelength $1.26 \mathrm{~cm}$; (c) - brightness temperature measured from the Gelendzik pier at the wavelength $1.35 \mathrm{~cm}$.
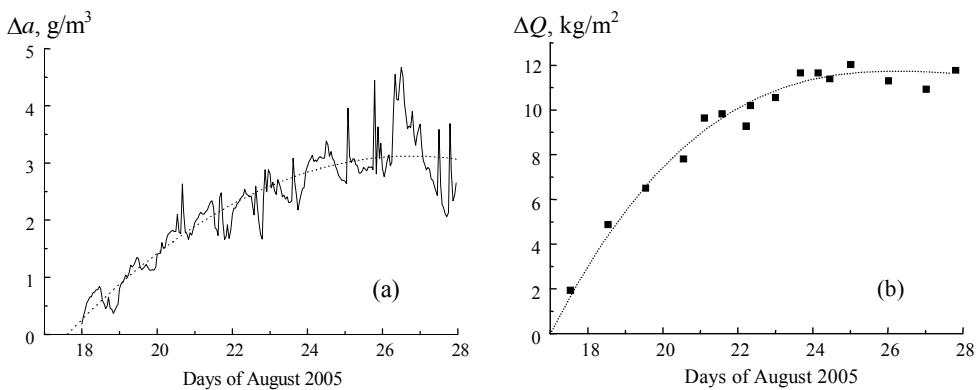

Figure 15. Variations of the absolute humidity of the near surface air $\Delta \mathrm{a}(\mathrm{a})$ and the total water vapor of the atmosphere $\triangle \mathrm{Q}$ (b) before the approach of Hurricane Katrina to the SMKF1 station. Dot lines - approximation of original results by polynomial of the 2 -th order.

\section{Conclusions}

The dynamics of different characteristics of the atmosphere in periods of activity of Hurricanes Katrina (August 2005) and Humberto (September 2007) was analyzed. This study is based on coupling the data of the buoy meteorological measurements with the data of simultaneous measurements from the DMSP SSM/I radiometer (in area of the NOAA station SMKF1) and the EOS-Aqua AMSR-E radiometer (in area of the station 42019). The technique of analysis of the atmosphere's integral characteristics such as its total water vapor content and enthalpy was developed. It enables determination of variations of the atmosphere temperature and humidity at its various horizons during the passing of Hurricane Katrina passed the station SMKF1 and the formation of Hurricane Humberto in the area of the station 42019. It is shown that in both cases the effect of taking off heat energy by hurricanes from the atmosphere and the ocean surface takes place. This effect results in strong disturbances of the temperature, humidity and pressure in the near-surface atmosphere and is accompanied by a sharp decrease of the atmosphere enthalpy and considerable increase of the vertical turbulent heat and moisture fluxes at the ocean surface.

The following features of the results of an analysis of the SOA parameters dynamics during the process of the formation of Hurricane Humberto can be noted, firstly the oscillating nature of behavior of the sensible and latent heat fluxes as well as the atmosphere integral water vapor after leaving by the formation location of the hurricane, i.e. at the stage of the SOA relaxation, secondly the availability of anomalies in behavior of the atmosphere integral water vapor the 4-5 days before an appearance of Hurricane Humberto. This leaves open to further research the question of what becomes of these anomalies as the hurricane passes. This research is required in order to further examine with observational data the processes 
of formation of other tropical hurricanes in various oceanic areas in various years and seasons taking into account the effect of the atmospheric horizontal circulation.

A good agreement between simulated and satellite estimates of the variations of the atmosphere water vapor content in areas of the stations SMKF1 and 42019 indicates that the adopted exponential model of vertical distribution of the air temperature and humidity provides useful information about dynamics of this integral characteristic of the atmosphere state, which is important for studying the influence of transient and developing tropical cyclones on the state of the system "ocean-atmosphere".

Results of the researches confirm a role of the atmospheric integral water vapor content, which is ease accessible in studying with modern satellite microwave radiometric means at the stages proceeding to development of the storm situations in the ocean and the sea, this is an important and required condition for studying the problems of the tropical cyclone genesis [14].

\section{Acknowledgements}

These investigations were conducted in a frame of the project on elaboration of technologies for the diagnosis of tropical hurricanes beginning in oceans. The project was maintained by the International Scientific and Technological Center (ISTC) in 2008-2011, grant no. 3827. We are grateful to Dr. Vladimir Krapivin, (V.A. Kotelnikov Institute of Radioengineering and Electronics RAS) and Dr E. Sharkov (Institute of Space Reseaches) for collaboration and useful discussions. We are also grateful to Dr. A. Lugovskoi for the assistance in our work.

\section{Author details}

A. G. Grankov, S. V. Marechek, A. A. Milshin, E. P. Novichikhin, S. P. Golovachev, N. K. Shelobanova and A. M. Shutko

*Address all correspondence to: agrankov@inbox.ru

Kotelnikov Institute of Radioengineering and Electronics Russian Academy of Sciences, Moscow, Russia

\section{References}

[1] Fedorov KN, Ginsburg AI. The Subsurface Layer of the Ocean, Leningrad, SSSR: Gidrometeoizdat; 1988 (in Russian).

[2] Hollinger PH, Peirce JL, Poe GA. SSM/I Instrument Evaluation. IEEE Transactions Geoscience Remote Sensing 199012 781-790. 
[3] Kawanishi T, Sezai T. Imaoka K et al. The Advanced Microwave Scanning Radiometer for the Earth Observing System (AMSR-E), NASDA's Contribution to the EOS for Global Energy and Water Cycle Studies. IEEE Transactions Geoscience Remote Sensing 200348 173-183.

[4] Kunkee D, Boucher D, G, Poe G, Swadley S. Evaluation of the Defence Meteorological Satellite Program (DMSP) Special Microwave Imager Sounder (SSMIS). In: proceedings of the IEEE International Symposium Geoscience and Remote Sensing Symposium (IGARSS2006) 7-12 July, Denver, Kolorado, 2006.

[5] Snopkov VG. On correlation between the atmosphere water vapor and the near surface humidity seasonal variations of the water vapor content over the Atlantic. Meteorol Gidrol 197712 38-42 (in Russian).

[6] Xrgian AX. Physics of the Atmosphere, vol.1. Leningrad, USSR: Gidrometeoizdat; 1978 (in Russian).

[7] Lappo SS, Gulev SK, Rozhdestvenskii AE. Large-scale Heat Interaction in the OceanAtmosphere System and Energy-Active Zones in the World Ocean. Leningrad, USSR: Gidrometeoizdat; 1990 (in Russian).

[8] Golytsyn GS. Polar Lows and Tropical Hurricanes: Their Energy and Sizes and a Quantitative Criterion for Their Generation. Izvestija, Atmosp. Oceanic Phys 2008 44(5) 579-590 (in Russian).

[9] Grankov AG, Milshin AA. Microwave Radiation of the Ocean-Atmosphere: Boundary Heat and Dynamic Interaction. Berlin, Germany: Springer-Verlag; 2010.

[10] Kharkevich AA. Bases of the Radioengineering (3-th edition). Moscow, Russia: Fizmatlit; 2007 (in Russian).

[11] Basharinov AE, Gurvich AS, Egorov ST. Radio Emission of the Planet Earth. Moscow, USSR: Fizmatlit (Nauka); 1974 (in Russian).

[12] Armand NA, Polyakov VM. Radio Propagation and Remote Sensing of the Environment. CRC Press LLC: Roca Raton; 2005.

[13] Alishouse JC, Snyder SA, Vongsatorn J, Ferrado RR. Determination of Oceanic Total Precipitate Water from the SSM/I. Journal Geophysical Researches 1990 28(5) 811-816.

[14] Sharkov AJ, Shramkov JN, Pokrovskaya IV. The Integral Water Vapor in Tropical Zone as the Necessary Condition for Atmospheric Catastrophic Genesis. Rem. Sens. Earth from Space. 2012, 2 73-82 (in Russian). 
